\title{
A pesquisa em história da educação: uma revisão de literatura
}

\section{Osnar da Costa ${ }^{I}$ Leonardo Salviano ${ }^{I I}$}

Resumo: O presente artigo desenvolve uma reflexão sobre a pesquisa em História da Educação, enfocando os debates sobre a historiografia em educação no Brasil e seus métodos investigativos em relação as suas fontes, métodos e práticas. Pretende-se apresentar as principais obras, os pesquisadores e suas contribuições para essa temática no âmbito do desenvolvimento educacional do país, se tornando, este objeto, numa divulgação destes trabalhos e sua influência no desempenho profissional de professores do país, bem como na sua apresentação mais antiga para a sua mais recente, e como, a partir daí, foram agregadas uma nova análise desse conhecimento, proporcionando assim, inovações nessa área.

Palavras-chave: Historiografia Brasileira, Pesquisa, História da Educação.

\section{The research in history of education: a literature review}

Abstract: The present article develops a reflection about the research in the history of the education, focusing the debates on the historiography in education in Brazil and its investigative methods in relation to its sources, methods and practices. It is intended to present the main works, the researchers and their contributions to this theme in the scope of the educational development of the country, becoming, in this object, a dissemination of these works and their influence on the professional performance of teachers of the country, as well as their presentation more recent to its most recent, and how, from that point on, a new analysis of this knowledge was added, thus providing innovations in this area.

Keywords: Brazilian Historiography, Research, History of Education.

Artigo recebido em 22/01/2018 e aprovado em 17/04/2018.

Cadernos do Tempo Presente, São Cristóvão-SE, v. 09, n. 01, p. 92-106, jan./jun. 


\title{
A PESQUISA EM HISTÓRIA DA EDUCAÇÃO: UMA REVISÃO DE LITERATURA
}

\author{
OSNAR DA COSTA \\ LEONARDO SALVIANO
}

\section{Considerações Iniciais}

O presente artigo tem por objetivo fazer alguns apontamentos e destacar tópicos relevantes acerca do tema A Pesquisa em História da Educação no Brasil. Para a abordagem desse tema é necessário refletir sobre a pesquisa historiográfica, os métodos e práticas usadas, como também, as fontes históricas, bem como questões referentes ao papel do pesquisador e sobre os seus artefatos que são de suma importância para uma análise ampla do objeto pesquisado.

Ao se entender o passado enquanto objeto de estudo, fica claro que não é uma tarefa fácil para o historiador desenvolver suas atividades. Isso porque o pesquisador em História não está devidamente "organizado" antes de ir a campo, ou mesmo da coleta prévia de dados. Cabe a ele (o historiador) ir à busca de vestígios que possam fornecer respostas e informações para a compreensão dos fatos. O historiador deve estar nessa procura constante, em busca de fontes que possam possibilitar o seu contato com experiências efetivadas ao longo do tempo. Caso contrário, a pesquisa fica sujeita a suposições e julgamentos dos fatos.

Tanto na historiografia como mais especificamente na História da Educação, durante muito tempo, havia uma concepção da utilização de fontes oficiais e escritas (legislação, discursões parlamentares, relatórios e atas escritas por autoridades, entre outras): "até por volta de 1850, à história continuou a ser, para os historiadores e para o público, um gênero literário"III . Essa comparação, entre a questão de fontes e o pensar positivista, foi sendo questionada e se deve da consideração da história como uma narrativa. Isso é o resultado do fato da longa predominância do positivismo na produção historiográfica. Assim, os trabalhos desses pesquisadores dessa época limitavam-se apenas a documentos e escritos.

Todavia, a partir do século XX, com o advento dos Annales, Revista Francesa de História, ocorreu uma grande revolução no que diz respeito aos tipos de fontes históricas, o pesquisador passa a contar com mais mecanismos que auxiliam em seu trabalho: fontes de natureza visual, oral e sonora foram também consideradas como fontes de pesquisa.

\begin{abstract}
A história faz-se com documentos escritos, sem dúvida. Quando estes existem. Mas pode fazer-se sem documentos escritos, quando não existem. Com tudo o que a habilidade do historiador lhe permite utilizar para fabricar o seu mel, na falta das flores habituais. Logo, com palavras. Signos. Paisagens e telhas. Com as formas do campo e das ervas daninhas. [..] Numa palavra, com tudo o que, pertencendo ao homem, depende do homem, serve ao homem, exprime o homem, demonstra a presença, a atividade, os gostos e as maneiras de ser do homem. Toda uma parte, e sem dúvida a mais apaixonante do nosso trabalho de historiadores, não consistirá num esforço constante para falar as coisas mudas, para fazê-las dizer o que elas por si próprias não dizem sobre os homens, sobre elas, aquela vasta rede de solidariedade e de entreajuda que supre a ausência do documento escrito? ${ }^{\mathrm{IV}}$
\end{abstract}

O historiador deve atenção também para no que diz respeito à origem desse documento quando usado. Quem o escreveu e de que maneira foi escrito, são pontos necessários a serem verificados pelo pesquisador. $\mathrm{Na}$ ausência deste documento, é

Cadernos do Tempo Presente, São Cristóvão-SE, v. 09, n. 01, p. 92-106, jan./jun. 2018| http://www.seer.ufs.br/index.php/tempo 


\title{
A PESQUISA EM HISTÓRIA DA EDUCAÇÃO: UMA REVISÃO DE LITERATURA
}

\author{
OSNAR DA COSTA \\ LEONARDO SALVIANO
}

enfático em dizer que quando não existem documentos escritos deve ser recorrida a outra fonte. Um caso particular nesta quebra paradigmática historiográfica, e que se tem como exemplo é a fonte oral, mesmo que ainda se tenha uma forte relutância no trabalho com este recurso pelos historiadores ${ }^{\mathrm{V}}$. A História Oral vem sendo de tal modo trabalhada, tanto pelos próprios historiadores cujos objetos de pesquisa são os mais diversos, quanto para aqueles que pesquisam a História da Educação de fato.

As fontes orais se baseiam exatamente no trabalho com pessoas vivas, mas principalmente com as tradições orais que são difundidas por anos ou até mesmo séculos. Por outro lado, se vê claramente que os usos das fontes orais estão sendo praticadas também na pesquisa em educação com um rigor muito consistente e dinâmico que faz com que tenhamos uma visualização sobre o que vinha ocorrendo na educação durante o passar do tempo, e sobre a reflexão dos desencadeamentos da atual conjuntura educacional do país.

Fora isto, sobre os critérios estabelecidos pela historiografia vigente que também intervém e contribui para a pesquisa em História da Educação, deve-se salientar de que este trabalho teve como fatores metodológicos a procura entre os meios de comunicação vigentes e bibliografia pertinente ao tema para construí-lo, ou seja, a ideia é a de fazer um panorama de como a pesquisa em História da Educação vem sendo trabalhada no Brasil.

\section{A Pesquisa Historiográfica e Suas Fontes}

A História de uma maneira geral é a compreensão dos fatos e os estudos acerca deles. Um quebra cabeça no sentido literal. Cabe ao pesquisador analisar e coletar dados sobre esses acontecimentos para assim chegar à compreensão do todo. Entretanto, vale ressaltar, que o historiador deve agir de boa-fé, não apenas por uma questão de querer ou não escrever a História.

No trabalho do historiador, como também do pesquisador em educação, é preciso um acúmulo de leitura para a construção das delimitações acerca da pesquisa em si. Essa leitura sempre é direcionada e relacionada com o momento atual vivido, onde escrevemos o passado a partir do presente, um e outro indissociável ${ }^{\mathrm{VI}}$. "Uma leitura do passado, por mais controlada que seja pela análise dos documentos, é sempre dirigida por uma leitura do presente"VII . No caso da pesquisa em História da Educação essa relação entre passado/presente é algo que se relaciona intrinsecamente, isso porque ao levar em consideração que retrata o historiador Jacques Le Goff sobre a questão de o passado referenciar o presente, e o presente ao passado, o que em termos historiográficos a História da Educação faz isso com veemência e precisão associativa.

De acordo com os estudos feitos, a partir da obra de Michel de Certeau, há a possibilidade de afirmar que escrever sobre a história de uma sociedade depende muito da escolha e da responsabilidade do historiador. Isso porque é ele que vai decidir o que exatamente vai pesquisar e como fará a pesquisa, que fontes e métodos serão usados em sua trajetória historiográfica, como também o recorte (delimitação) de um fato ou acontecimento histórico. Além de decidir qual a linha teórica a ser utilizada na análise e compreensão dos fatos. Feita a escolha do fato histórico, o historiador demarca um acontecimento da vida social baseando-se sempre numa teoria de referência.

Cadernos do Tempo Presente, São Cristóvão-SE, v. 09, n. 01, p. 92-106, jan./jun. 2018| http://www.seer.ufs.br/index.php/tempo 


\title{
A PESQUISA EM HISTÓRIA DA EDUCAÇÃO: UMA REVISÃO DE LITERATURA
}

\author{
OSNAR DA COSTA \\ LEONARDO SALVIANO
}

\begin{abstract}
[...] A interpretação das fontes, as teorias assumidas pelo historiador para a compreensão do passado são, e continuarão sendo, momentos fundamentais do trabalho historiográfico. [...] Afinal de contas, os documentos, como alguns já disseram, não falam por si, os historiadores obrigam que eles falem, inclusive de seus próprios silêncios ${ }^{\mathrm{VIII}}$.
\end{abstract}

O estudo das fontes históricas é uma ferramenta importante para o entendimento sobre como fazer trabalhos em História, e é utilizada na compreensão dos fatos. Consistem no levantamento de discursos políticos, documentos oficiais, memórias e outros. Vale ressaltar que o pesquisador pode escolher em usar duas metodologias para a análise, a primeira é observar essa fonte como objeto de estudo a partir de uma vista imediata; e a outra na compreensão dos fatos históricos, a essência desse fato, usando assim, um olhar mais complexo, amplo, não se resumindo apenas numa observação da aparência dessa fonte que é ofertada ao historiador de forma imediata. De um modo geral, a fonte nada mais é que a matéria-prima do historiador. Entretanto deve certificarse que:

Em sua inteireza e completude, o passado nunca será plenamente conhecido e compreendido; no limite, podemos entendê-lo em seus fragmentos, em suas incertezas. Por mais que o pesquisador tente se aproximar de uma verdade sobre o passado, apostando no rigor metodológico, permanecem sempre fluidos e fugidios os pedaços de história que se quer reconstruir ${ }^{\mathrm{IX}}$.

Assim sendo, cabe ao historiador em não apenas resgatar o passado, mas também ele assume a tarefa de interpretá-lo. Uma tarefa extremamente cansativa, pois ele deve, portanto, ser imparcial, mesmo sabendo da questão divergente científica que ainda questiona esse fator da imparcialidade, principalmente quando relacionamos este pensamento ao que argumenta Le Goff ${ }^{\mathrm{X}}$ sobre a relação passado/presente/futuro. Em seu ofício, estarão evidentemente vários casos a serem filtrados por ele: as crenças de um determinado povo, seus ideais de vida, o processo de formação de uma determinada sociedade, como também as ocorrências por parte da educação.

Portanto o historiador em História da Educação entra nesse contexto sabendo que não deverá em nenhum momento julgar, mas entender tais processos observados através das fontes analisadas e levantar questões em relação ao passado vivido. É falando sobre a definição da fonte que Saviani ${ }^{\mathrm{XI}}$ nos relata sobre sua importância para os pesquisadores:

\begin{abstract}
As fontes estão na origem, constituem o ponto de partida, a base, o ponto de apoio da construção historiográfica que é a reconstrução, no plano do conhecimento, do objeto histórico estudado. Assim, as fontes históricas não são a fonte da história, ou seja, não é delas que brota e flui a história. Elas, enquanto registros, enquanto testemunhos dos atos históricos, são a fonte do nosso conhecimento histórico, isto é, é delas que brota, é nelas que se apoia o conhecimento que produzimos a respeito da história.
\end{abstract}

No entanto, Bacellar ${ }^{\mathrm{XII}}$ alerta ao historiador que, antes de qualquer coisa, ele analise com um olhar crítico essa fonte, questione e nunca se submeta a ela: “[...] antes

Cadernos do Tempo Presente, São Cristóvão-SE, v. 09, n. 01, p. 92-106, jan./jun. 2018| http://www.seer.ufs.br/index.php/tempo 


\title{
A PESQUISA EM HISTÓRIA DA EDUCAÇÃO: UMA REVISÃO DE LITERATURA
}

\author{
OSNAR DA COSTA \\ LEONARDO SALVIANO
}

de tudo, ser historiador exige que se desconfie das fontes, das intenções de quem a produziu, somente entendidas com o olhar crítico e a correta contextualização do documento que se tem em mãos"XIII. A desconfiança e a incerteza fazem parte de uma constante para qualquer pesquisador, logo o critério e o rigor envolvidos ditam tais exigências para que de fato não ocorram erros que posteriormente serão corrigidos por aqueles que possuem este empenho.

Como parte principal do ofício, inicialmente, é necessário que o historiador delimite seu espaço de pesquisa colocando em consideração também o período de tempo, para então partir para a escolha da fonte a ser usada. Deve-se salientar que uma fonte pode ser utilizada diversas vezes e principalmente, por pesquisadores diversos. Isso porque o ponto de partida não são as fontes, mas sim a pergunta da questão proposta que o pesquisador deseja responder. Em seu trabalho deve problematizar metodologicamente pela investigação.

[...] são as perguntas que o pesquisador tem a fazer ao material que lhe conferem sentido e, no limite, enquanto houver perguntas, o material não está suficientemente explorado. Nesse sentido é que se diz que uma fonte nunca está esgotada e que a história é sempre reescrita, na medida em que depende do problema proposto a ser enfrentado e, portanto, do tipo de pergunta que lhe é formulada. Esta, por sua vez, é sempre resultado de um olhar que, do presente, o pesquisador (a) lança ao passado ${ }^{\mathrm{XIV}}$.

Desta forma, o historiador deve ter um olhar sempre acurado para os documentos de sua pesquisa, deve-se através de suas fontes sejam elas: relatórios, jornais, documentos ou outros, possibilitar a descoberta do passado, buscar um novo olhar, minucioso e diferente sobre essas fontes historiográficas. Sobre o trabalho de pesquisa historiográfica em História da Educação pode-se dizer que,

O trabalho com as fontes exige, antes de tudo, paciência. [...] O cruzamento e confronto das fontes poderá também ajudar no controle da subjetividade do pesquisador. É uma operação indispensável. Há uma expressão antiga que diz bastante bem do incansável trabalho que se há de ter com o entretecer do problema, com as questões formuladas e a ida às fontes: "da bigorna à forja, da forja à bigorna" ${ }^{\mathrm{XV}}$.

Então, tendo em vista os estudos desta temática, entende-se que o historiador deva definir seus próprios métodos apoiados em uma estrutura teórica e coerente em relação as suas fontes. A pesquisa em História da Educação não é apenas relatos ou narrativas do tempo escolar, mas sim premissas teóricas apresentadas como resultado da própria pesquisa histórica.

\section{A pesquisa em educação no Brasil}

O debate sobre a historiografia educacional brasileira ainda é muito recente, apesar de sua longevidade na história. Surgiu com os estudos sobre a produção no campo da educação no embalo da criação e consolidação dos programas de pósgraduações, mas já por outro lado também terá um estímulo das associações e instituições de pesquisa na área de educação.

Cadernos do Tempo Presente, São Cristóvão-SE, v. 09, n. 01, p. 92-106, jan./jun. 2018| http://www.seer.ufs.br/index.php/tempo 


\title{
A PESQUISA EM HISTÓRIA DA EDUCAÇÃO: UMA REVISÃO DE LITERATURA
}

\author{
OSNAR DA COSTA \\ LEONARDO SALVIANO
}

\begin{abstract}
Se a primeira universidade nasce em 1920 - a Universidade do Rio de Janeiro (URJ, atual UFRJ) -, e a segunda em 1927 - a Universidade de Minas Gerais (UMG, atual UFMG), as primeiras publicações sobre a História da Educação no Brasil remontam aos finais do século XIX. Certamente, não haveria correlação entre tais dimensões, porém tais publicações revelam preocupações com a educação nacional, uma locução componente do vocabulário político brasileiro apenas ao final do século XIX. E a História da Educação estaria aí sendo compreendida e contribuinte para a busca de uma identidade nacional $^{\mathrm{XVI}}$.
\end{abstract}

Desta forma, este estímulo é gerado através de uma articulação em âmbito nacional dessas instituições para promover um maior estudo sobre a historiografia educacional no Brasil, pois de 1978 a 1998 os principais trabalhos elaborados sobre a História da Educação são limitados. Conforme segue de acordo com José Claudinei Lombardi ${ }^{\mathrm{XVII}}$ em ordem cronológica:

1978 - MARIA LUIZA DOS SANTOS RIBEIRO publicou o livro resultante de sua dissertação de mestrado, introdução à História da Educação brasileira;

1981 - GILBERTO LUIZ ALVES defendeu sua dissertação de mestrado que levou por título Da história a História da Educação;

1984 - Publicação do artigo de MIRIA, JORGE WARDE, “Anotações para uma historiografia da educação brasileira";

1986 - ELIANE MARTA TEIXEIRA LOPES, Perspectivas históricas para educação";

1990 - NOVO ARTIGO DE MIRIAN JORGE WARDE, "Contribuição da história para educação".

1990 - PAULO GHIRALDELLI JUNIOR iniciou a publicação de vários trabalhos sobre a história e a historiografia da educação. É desse ano o artigo "notas sobre as possibilidades da historiografia marxista da educação";

1993 - JOSE CLAUDINEI LOMBARDI defendeu sua tese de doutorado com o título marxismo e história: algumas reflexões sobre a historiografia educacional brasileira recente;

1995 - LUIZ CARLOS BARREIRA defendeu sua tese de doutorado intitulada História e historiografia: as escritas recentes da História da Educação brasileira (1971 -1978);

1995 - BRUNO BONTEMPI JUNIOR defendeu sua dissertação de mestrado, História da Educação brasileira: o terreno do consenso.

1996 - CLARICE NUNES, "Ensino e historiografia da educação: problematização de uma hipótese";

1998 - NEDINA STEIN apresentou sua dissertação de mestrado, orientada por Luiz C. Barreira ${ }^{\text {XVIII }}$.

Todos esses trabalhos fazem uma análise e investigação sobre a historiografia educacional brasileira em uma perspectiva mais ampla, buscando alavancar e redirecionar os estudos e pesquisas em História da Educação, porém, deve-se também incluir a colaboração de eventos que ajudaram e tiveram a preocupação de impulsionar a pesquisa nacional, como por exemplo, o ocorrido em 1984 de cunho historiográfico para a educação.

Cadernos do Tempo Presente, São Cristóvão-SE, v. 09, n. 01, p. 92-106, jan./jun. 2018| http://www.seer.ufs.br/index.php/tempo 


\title{
A PESQUISA EM HISTÓRIA DA EDUCAÇÃO: UMA REVISÃO DE LITERATURA
}

\author{
OSNAR DA COSTA \\ LEONARDO SALVIANO
}

Em 1984 promovido pelo INEP (Instituto Nacional de Estudos e Pesquisas Educacionais Anísio Teixeira), em setembro, foi ministrado o Seminário sobre Historiografia e Educação. Esse evento promovido pelo INEP foi realizado pela direção do órgão com plenos objetivos de entender que existiam "lacunas consideráveis na História da Educação face ao desenvolvimento da historiografia contemporânea no Brasil" e "na verificação de que o desconhecimento da área vem comprometer sensivelmente a formação de educadores", este evento ainda permanece em aberto desde $1984^{\mathrm{XIX}}$.

Neste evento, o INEP demostrou uma grande preocupação quanto à problemática teórico-metodológica das pesquisas na área da educação e pretendia avaliá-las. No mesmo evento o INEP informou que daria apoio à História da Educação brasileira, pois as renovações teórico-metodológicas apresentadas pela pesquisa educacional não demostraram um significativo número de estudos em História da Educação. Assim seu objetivo era intensificar os estudos na área da historiografia educacional brasileira $\mathrm{xX}$.

Podemos destacar ainda a Associação Nacional de Pós-graduação e Pesquisa em Educação (ANPEd) que desde a década de 1980 tornou-se um espaço de discussão no campo educacional e também a criação do Grupo de Estudos e Pesquisas "História, Sociedade e Educação no Brasil", popularmente conhecido como: HISTEDBR. Este último, criado em 1986, hoje independente da ANPEd, foi sediado na Universidade Estadual de Campinas (UNICAMP), e é um coletivo nacional de pesquisa que tem realizado diversos eventos, seminários e palestras que vem articulando a participação de grupos de trabalho voltado exclusivamente para a área de História da Educação. Um aspecto importante de ressaltarmos é o fato de ser incluindo vários estados brasileiros. Conforme informações obtidas no site do grupo, dados do último cadastramento feito em julho de 2006, são 24 (vinte e quatro) GTs (grupos de trabalho) localizados em 13 Estados do Brasil.

Esse grupo contou e conta com a participação de professores e alunos de mestrado e doutorado, com o objetivo de propiciar o intercâmbio das pesquisas que estavam sendo desenvolvidas nos cursos de pós-graduação. Tem como coordenador geral o Professor Dr. Dermeval Saviani e coordenador executivo o professor Dr. José Claudinei Lombardi. Desde 1991 o grupo passou a investir na promoção de Seminários sobre o tema, como pode se notar nos quadros 01 e 02 :

Cadernos do Tempo Presente, São Cristóvão-SE, v. 09, n. 01, p. 92-106, jan./jun. 2018| http://www.seer.ufs.br/index.php/tempo 
OSNAR DA COSTA

LEONARDO SALVIANO

Quadro 01: Edições do Seminário Nacional de Estudos e Pesquisas "História, Sociedade e Educação no Brasil" entre os anos: 1991-2009.

\begin{tabular}{|c|c|c|c|c|c|}
\hline Evento & Periodicidade & Edições & Ano & Cidade & Estado \\
\hline $\begin{array}{l}\text { Seminário } \\
\text { Nacional de } \\
\text { Estudos e } \\
\text { Pesquisas ", } \\
\text { História, } \\
\text { Sociedade e } \\
\text { Educação no } \\
\text { Brasil", } \\
\text { Promoção: } \\
\text { Grupo de } \\
\text { Estudos e } \\
\text { Pesquisas ", } \\
\text { História, } \\
\text { Sociedade e } \\
\text { Educação no } \\
\text { Brasil", }\end{array}$ & - & $\begin{array}{l}1^{a} \\
2^{a} \\
3^{a} \\
4^{a} \\
5^{a} \\
6^{a} \\
7^{a} \\
8^{a}\end{array}$ & $\begin{array}{l}1991 \\
1992 \\
1995 \\
1997 \\
2001 \\
2003 \\
2006 \\
2009\end{array}$ & $\begin{array}{c}\text { Campinas } \\
\text { Campinas } \\
\text { Campinas } \\
\text { Campinas } \\
\text { Campinas } \\
\text { Aracaju } \\
\text { Campinas } \\
\text { Campinas }\end{array}$ & $\begin{array}{c}\text { São Paulo } \\
\text { São Paulo } \\
\text { São Paulo } \\
\text { São Paulo } \\
\text { São Paulo } \\
\text { Sergipe } \\
\text { São Paulo } \\
\text { São Paulo }\end{array}$ \\
\hline
\end{tabular}

Fonte $^{\mathrm{XXI}}$

Quadro 02: Edições das Jornadas do Grupo: HISTEDBR Entre os anos: 20022011

\begin{tabular}{|c|c|c|c|c|c|}
\hline Evento & Periodicidade & Edições & Ano & Cidade & Estado \\
\hline $\begin{array}{l}\text { Jornadas do } \\
\text { HISTEDBR } \\
\text { Promoção: Grupo } \\
\text { de Estudos e } \\
\text { Pesquisas ", } \\
\text { História, Sociedade } \\
\text { e Educação no } \\
\text { Brasil', }\end{array}$ & - & $\begin{array}{l}1^{\mathrm{a}} . \\
2^{\mathrm{a}} \\
3^{\mathrm{a}} . \\
4^{\mathrm{a}} . \\
5^{\mathrm{a}} \\
6^{\mathrm{a}} \\
7^{\mathrm{a}} \\
8^{\mathrm{a}} \\
9^{\mathrm{a}} . \\
10^{\mathrm{a}} .\end{array}$ & $\begin{array}{l}2002 \\
2002 \\
2003 \\
2004 \\
2005 \\
2005 \\
2007 \\
2008 \\
2009 \\
2011\end{array}$ & $\begin{array}{c}\text { Salvador } \\
\text { Ponta Grossa } \\
\text { Americana } \\
\text { Maringá } \\
\text { Sorocaba } \\
\text { Ponta Grossa } \\
\text { Campo Grande } \\
\text { São Carlos } \\
\text { Campinas } \\
\text { Feira de Santana }\end{array}$ & $\begin{array}{c}\text { Bahia } \\
\text { Paraná } \\
\text { São Paulo } \\
\text { Paraná } \\
\text { São Paulo } \\
\text { Paraná } \\
\text { Mato Grosso do Sul } \\
\text { São Paulo } \\
\text { São Paulo } \\
\text { Bahia }\end{array}$ \\
\hline
\end{tabular}

Fonte $^{\mathrm{XX}}$

O quadro abaixo mostra a situação da pesquisa em História da Educação no Rio Grande do Sul, os dados são mais recentes de acordo com o artigo de Alessandro Carvalho Neto ${ }^{\text {XIII }}$ que totalizadas são apenas 23 produções nos últimos 10 anos em programas de Pós-Graduação das universidades brasileiras, o que significa que o acervo historiográfico sobre essa temática ainda é bastante reduzido.

Cadernos do Tempo Presente, São Cristóvão-SE, v. 09, n. 01, p. 92-106, jan./jun. 2018| http://www.seer.ufs.br/index.php/tempo 
OSNAR DA COSTA

LEONARDO SALVIANO

\begin{abstract}
QUADRO 03: Pesquisa no Banco de teses da capes - Dissertações e Teses defendidas entre 2001 e 2010 relacionadas à História da Educação no RS Mestrado/Doutorado
\end{abstract}

\begin{tabular}{|l|l|l|l|l|l|l|l|l|l|l|}
\hline Descritores & $\mathbf{2 0 0 1}$ & $\mathbf{2 0 0 2}$ & $\mathbf{2 0 0 3}$ & $\mathbf{2 0 0 4}$ & $\mathbf{2 0 0 5}$ & $\mathbf{2 0 0 6}$ & $\mathbf{2 0 0 7}$ & $\mathbf{2 0 0 8}$ & $\mathbf{2 0 0 9}$ & Total \\
\hline $\begin{array}{l}\text { História } \\
\text { da Educação no RS }\end{array}$ & - & $01 / 00$ & - & $01 / 00$ & - & $01 / 00$ & - & $02 / 01$ & $02 / 00$ & $07 / 01$ \\
\hline $\begin{array}{l}\text { História } \\
\text { daEducação em Bagé }\end{array}$ & - & - & - & - & - & - & - & - & - & - \\
\hline $\begin{array}{l}\text { Primeira } \\
\text { República no RS }\end{array}$ & - & $01 / 00$ & - & - & $00 / 01$ & - & $03 / 00$ & $01 / 00$ & - & $05 / 01$ \\
\hline $\begin{array}{l}\text { Instrução } \\
\text { Pública no RS }\end{array}$ & - & - & - & - & - & - & - & - & - & - \\
\hline $\begin{array}{l}\text { Educação Primária no } \\
\text { RS no }\end{array}$ & - & - & - & - & - & - & - & - & - & - \\
\hline $\begin{array}{l}\text { Educação } \\
\text { Primária em Bagé }\end{array}$ & - & - & - & - & - & - & - & - & - & - \\
\hline $\begin{array}{l}\text { Partido Republicano } \\
\text { Rio-grandense }\end{array}$ & $01 / 00$ & - & - & - & - & - & $00 / 01$ & - & - & $01 / 01$ \\
\hline $\begin{array}{l}\text { Positivismo } \\
\text { e Educação }\end{array}$ & $01 / 01$ & - & $00 / 01$ & $02 / 00$ & $01 / 00$ & - & - & - & - & $04 / 01$ \\
\hline $\begin{array}{l}\text { Castilhismo } \\
\text { e Educação }\end{array}$ & - & & & & $01 / 01$ & - & - & - & - & $01 / 01$ \\
\hline Total & & & & & & & & & & $18 / 05$ \\
\hline
\end{tabular}

Fonte $^{\mathrm{XXIV}}$

Logo mais abaixo, demonstraremos em um quarto quadro o quantitativo dos grupos de pesquisa que abordam a História da Educação e que possuem registro no $\mathrm{DGP} / \mathrm{CNPq}^{\mathrm{XXV}}$, com base nos dados de 2011. Ao observar, se parte para uma análise em números quantitativos, nota-se uma maior concentração de grupos no eixo Sul e Sudeste do país, em comparação das regiões Norte/Nordeste e Centro-Oeste. Neste caso a busca partiu para obtenção de uma resposta para esse questionamento, ou seja - de como vem sendo pesquisada a História da Educação a partir do contexto das regiões.

Através da análise, se pode afirmar, que por determinados aspectos, como o geográfico, à concentração industrial, urbana e relativa ao quantitativo de instituições públicas que se voltam para a pós-graduação são mais dispostas em termos de trabalhos com referência à pesquisa em História da Educação. Sob a análise do Quadro 03, disponibilizado pelo DGP/CNPq, no total têm-se 345 grupos de pesquisa registrados e distribuídos nos seguintes estados brasileiros em 2011.

Cadernos do Tempo Presente, São Cristóvão-SE, v. 09, n. 01, p. 92-106, jan./jun. 2018| http://www.seer.ufs.br/index.php/tempo 


\section{A PESQUISA EM HISTÓRIA DA EDUCAÇÃO: UMA REVISÃO DE LITERATURA}

OSNAR DA COSTA

LEONARDO SALVIANO

QUADRO 04: Quantitativo dos Grupos de Pesquisa em História da Educação ou que abordam a História da Educação registrada no DGP/CNPq em 2011, com distribuição conforme o número de grupos por unidade da federação.

\begin{tabular}{|c|c|c|c|c|c|}
\hline \multicolumn{2}{|c|}{ De 00 a 05 Grupos de Pesquisa } & \multicolumn{2}{|c|}{ De 06 a 15 Grupos de Pesquisa } & \multicolumn{2}{|c|}{ Acima de 20 Grupos de Pesquisa } \\
\hline $\begin{array}{l}\text { Unidade da } \\
\text { Federação }\end{array}$ & $\begin{array}{l}\text { Número de } \\
\text { Grupos de } \\
\text { Pesquisa }\end{array}$ & $\begin{array}{l}\text { Unidade da } \\
\text { Federação }\end{array}$ & $\begin{array}{c}\text { Número de } \\
\text { Grupos de } \\
\text { Pesquisa }\end{array}$ & $\begin{array}{l}\text { Unidade da } \\
\text { Federação }\end{array}$ & $\begin{array}{l}\text { Número } \\
\text { de Grupos } \\
\text { de } \\
\text { Pesquisa }\end{array}$ \\
\hline Tocantins & 05 & Santa Catarina & 15 & São Paulo & $\begin{array}{l}6 \\
2\end{array}$ \\
\hline Sergipe & 05 & Mato Grosso do Sul & 15 & Paraná & $\begin{array}{l}4 \\
1\end{array}$ \\
\hline Mato Grosso & 05 & Goiás & 11 & Rio de Janeiro & $\begin{array}{l}3 \\
5\end{array}$ \\
\hline Piauí & 04 & Rio Grande do Norte & 11 & Minas Gerais & $\begin{array}{l}3 \\
3\end{array}$ \\
\hline Alagoas & 04 & Pará & 10 & Bahia & $\begin{array}{l}2 \\
3\end{array}$ \\
\hline Rondônia & 03 & Paraíba & 09 & Rio Grande do Sul & $\begin{array}{l}2 \\
2\end{array}$ \\
\hline Distrito Federal & 03 & Ceará & 08 & - & - \\
\hline Amazonas & 03 & Espírito Santo & 06 & - & - \\
\hline Acre & 00 & Pernambuco & 06 & - & - \\
\hline Alagoas & 00 & Maranhão & 06 & - & - \\
\hline Amapá & 00 & - & - & - & - \\
\hline Roraima & 00 & - & - & - & - \\
\hline Total & 32 & Total & 97 & Total & 216 \\
\hline
\end{tabular}

Fonte $^{\mathrm{XXV}}$

Em 1999 foi criada a Sociedade Brasileira em História da Educação, que logo após de um longo processo de discussões vem realizando congressos bianuais, contando com a participação efetiva de vários professores de História da Educação de todo o país desde o ano 2000.

Esta sociedade tem grande importância para a pesquisa em História da Educação no Brasil, pois a mesma conta com o apoio de diversos pesquisadores de todas as regiões brasileiras, estimulando, por exemplo, eventos, seminários, cursos e outras iniciativas similares, podendo interagir com associações congêneres com vistas à atualização do conhecimento e à socialização das experiências realizadas na área.

Cadernos do Tempo Presente, São Cristóvão-SE, v. 09, n. 01, p. 92-106, jan./jun. 2018| http://www.seer.ufs.br/index.php/tempo 


\title{
A PESQUISA EM HISTÓRIA DA EDUCAÇÃO: UMA REVISÃO DE LITERATURA
}

\author{
OSNAR DA COSTA \\ LEONARDO SALVIANO
}

\begin{abstract}
A RBHE, publicada a partir de 2001, segue em circulação de forma regular e ininterrupta, enquanto que as coleções Documentos e Horizontes foram responsáveis pela publicação de 25 volumes, seja na forma de impressos ou de e-books. Ao longo dos anos, a SBHE destacou-se no apoio ao desenvolvimento da pesquisa e do ensino na área, tarefas estas inscritas entre os seus objetivos institucionais. No cenário internacional a SBHE tem assumido o papel de interlocutora e articuladora da comunidade de pesquisadores brasileiros em relação às inúmeras demandas relacionadas aos eventos científicos, publicações e projetos integrados com a comunidade internacional $^{\mathrm{XXVII}}$.
\end{abstract}

É importante ressaltar também, a influência de uma "Nova" historiografia educacional brasileira, que tendo em vista novas concepções de ciência, se tornaram tendência no campo de investigação e influenciaram nas abordagens e concepções metodológicas da história na pesquisa em educação. Essas novas concepções de ciência são estimuladas a partir das análises do livro de Thomas S. Kuhn, "A estrutura das revoluções científicas", editado no Brasil só em 1972.

Para Kuhn, foram as dúvidas e dificuldades com relação à elaboração da historiografia da ciência tradicional que provocaram "uma revolução historiográfica no estudo da ciência", pela qual os historiadores começaram a se colocar "novas questões" e a pressupor a possibilidade de outras formas de desenvolvimento (não cumulativas) do conhecimento científico (idem, p. 22). Foi o próprio autor que denominou esse tipo de abordagem de "nova historiografia" e explicou que o objetivo da nova concepção era buscar "uma nova imagem da ciência"XXVIII .

Desta forma, essa nova historiografia e concepção de ciência passaram a dominar a pesquisa e novas questões do desenvolvimento do conhecimento científico na História da Educação trazendo "novas" tendências e uma pregação da necessidade de novos "problemas" para a pesquisa educacional e uma nova análise do conhecimento, de fatos e fontes, introduzindo inovações na pesquisa dessa área.

Quanto aos periódicos científicos de história em educação no Brasil, atualmente são quatro com periodicidade regular e com pioneirismo em História da Educação. Vinculada à ASPHE (Associação Sul Rio-Grandense de Pesquisadores em História da Educação) e criados entre 1997 e 2002 alcançou a publicação de trinta e cinco números em 2011, estes quatro periódicos aparecem descritos no Quadro apresentado a seguir:

Cadernos do Tempo Presente, São Cristóvão-SE, v. 09, n. 01, p. 92-106, jan./jun. 2018| http://www.seer.ufs.br/index.php/tempo 
A PESQUISA EM HISTÓRIA DA EDUCAÇÃO: UMA REVISÃO DE LITERATURA

OSNAR DA COSTA

LEONARDO SALVIANO

QUADRO 05: Periódicos brasileiros atuais, com periodicidade regular, vinculados à área de História da Educação.

\begin{tabular}{|c|c|c|c|c|}
\hline $\begin{array}{l}\text { Início da } \\
\text { publicação }\end{array}$ & Título & $\begin{array}{l}\text { Periodicidade } \\
\text { atual }\end{array}$ & Endereço eletrônico atual & Vinculação \\
\hline 1997 & $\begin{array}{l}\text { História da } \\
\text { Educação }\end{array}$ & Quadrimestral & http://seer.ufrgs.br/asphe & $\begin{array}{lr}\text { Associação Sul Rio- } \\
\text { Grandense } & \text { de } \\
\text { Pesquisadores } & \text { em } \\
\text { História da Educação } \\
\text { (ASPHE) }\end{array}$ \\
\hline 2000 & $\begin{array}{l}\text { Revista } \\
\text { HISTEDBR } \\
\text { OnLine }\end{array}$ & Trimestral & $\begin{array}{l}\text { http://www.fe.unicamp.br/ } \\
\text { histedbr/index.php }\end{array}$ & $\begin{array}{l}\text { Grupo de Estudo e } \\
\text { Pesquisas "História, } \\
\text { Sociedade e Educação } \\
\text { no } \\
\text { (HISTEDBR) }\end{array}$ \\
\hline 2001 & $\begin{array}{ll}\text { Revista } & \\
\text { Brasileira } & \text { de } \\
\text { História } & \text { da } \\
\text { Educação } & \end{array}$ & Quadrimestral & http://www.sbhe.org.br & $\begin{array}{ll}\text { Sociedade } & \text { Brasileira } \\
\text { História da } \\
\text { (SBHE) }\end{array}$ \\
\hline 2002 & $\begin{array}{ll}\text { Cadernos } & \text { de } \\
\text { História } & \text { da } \\
\text { Educação } & \end{array}$ & Semestral & $\begin{array}{l}\text { http://www.seer.ufu.br/index. } \\
\text { php/che/ }\end{array}$ & $\begin{array}{l}\text { Núcleo de Estudos e } \\
\text { Pesquisas em História } \\
\text { e Historiografia da } \\
\text { Educação da } \\
\text { Universidade Federal } \\
\text { de Uberlândia } \\
\text { (NEPHEUFU) }\end{array}$ \\
\hline
\end{tabular}

Outros periódicos brasileiros também vinculados às áreas de Educação e de História têm trazido regularmente em seus números artigos que facultem a História da Educação:

Revista Brasileira da Educação (ANPED), Revista Educação e Sociedade (CEDES), Cadernos de Pesquisa (FCC), Teoria \& Educação (Pannonica), Educação \& Filosofia (UFU), Educação em Revista (UFMG), Revista Brasileira de Estudos Pedagógicos (INEP), Em Aberto (INEP), Revista Brasileira de História (ANPUH), Contemporaneidade e Educação (IEC), Educação em Foco (UFJF), Educação (Unisinos), Revista USP, Série Estudos (UCDB), Horizontes (USF), Teias (UERJ), entre outras ${ }^{\mathrm{XXX}}$.

As revistas que trabalham com História da Educação não precisam necessariamente, no título da revista especificar que trabalham com foco e escopo dentro do que conhecemos como historiografia da educação. Sendo que o que Carvalho ${ }^{\mathrm{XXI}}$ comentou faz com o que se especifique revistas científicas cujos trabalhos também permeiam sobre a temática, seja no seu foco ou escopo, em dossiês propostos ou em edições específicas.

O que temos hoje em termos de História da Educação advém exatamente da fundamentação e iniciativa de cursos de pós-graduação na criação de revistas científicas, congressos e seminários, tanto que também muitos meios acadêmicos de circulação nacional que estão ligados à educação ou a própria historiografia sobre a

Cadernos do Tempo Presente, São Cristóvão-SE, v. 09, n. 01, p. 92-106, jan./jun. 2018| http://www.seer.ufs.br/index.php/tempo 


\section{A PESQUISA EM HISTÓRIA DA EDUCAÇÃO: UMA REVISÃO DE LITERATURA}

\section{OSNAR DA COSTA \\ LEONARDO SALVIANO}

mesma, estão de algum modo se abrindo e possibilitando que mais trabalhos neste ramo sejam conhecidos e divulgados no meio acadêmico.

\section{Considerações Finais}

Pelo que foi colocado e estudado durante todo o processo de construção desse trabalho, pode-se afirmar, que a pesquisa histórico-educacional no Brasil está vinculada ao desenvolvimento da universidade brasileira. É paulatinamente estimulado a partir de iniciativas coletivas, de instâncias universitárias e de órgãos públicos ligados ao Ministério da Educação do Brasil.

O que também se destacou aqui é o processo de pesquisa historiográfica na área da educação no Brasil e algumas das principais obras e pesquisadores que contribuíram para a criação desse acervo no período de 1978-1998. Vários fatores colaboraram para despertar o interesse na pesquisa em História da Educação, notou-se isto nos dados relativos ao aumento de grupos de pesquisa em todo o país que está registrado no DGP/CNPq no ano de 2011, e que pelo acesso recente em 2017 se vê claramente que a tendência será de superar estes índices.

Com o desencadeamento no século XX da Escola dos Annales, a nova historiografia foi aos poucos introduzindo questões do desenvolvimento do conhecimento para a pesquisa no âmbito educacional, que em termos práticos contribui para pensar a educação contemporânea e entendê-la de modo a pegar aquilo que durante certo período deu certo, e excluir aquilo que não servirá mais se for aplicado hoje.

Percebe-se também, a partir daí, que foram agregadas uma nova análise desse conhecimento, proporcionando assim inovações nessa área, o que os periódicos científicos vêm fazendo com qualidade e perspicácia na seleção e contribuição real do fator que a História da Educação influi dentro deste quadro de produção acadêmica.

De um modo geral, a pesquisa educacional está muito bem relacionada ao desenvolvimento da universidade brasileira e, de uma maneira tímida, vagarosa, foi sendo vista por iniciativas individuais e coletivas. A criação de grupos, organizações e associações de pesquisas voltadas para a historiografia da educação foi de fato de grande importância, pois assim, o campo da História da Educação ganhou mais autonomia, tornando-se um dos mais importantes na área da educação. Podemos ressaltar que esse processo investigativo, na história educacional, demandou tempo e dedicação de pesquisadores brasileiros e dentre estes, alguns não tinham uma relação estreita e de uma maneira direta para com a área de História da Educação, mas que por outro lado, acabaram ajudando no fortalecimento e crescimento da pesquisa na área.

Agradecimento: Externamos nossos sinceros agradecimentos a Luiz Eude R. Santana por sua participação nesta pesquisa, que por ter se dissociado do curso de História, não dera prosseguimento a este estudo, o que em prática fizera muito por ele enquanto se dispôs na pesquisa documental.

Cadernos do Tempo Presente, São Cristóvão-SE, v. 09, n. 01, p. 92-106, jan./jun. 2018| http://www.seer.ufs.br/index.php/tempo 


\section{A PESQUISA EM HISTÓRIA DA EDUCAÇÃO: UMA REVISÃO DE LITERATURA}

\section{OSNAR DA COSTA}

LEONARDO SALVIANO

\section{Notas}

${ }^{\text {I }}$ Mestre em Educação e Licenciado em História - Universidade de Pernambuco Campus Petrolina.

II Licenciando em História pela Universidade de Pernambuco Campus Petrolina.

III (LANGLOIS; SEIGNOBOS, 1946).

IV (LE GOOF, 2003).

$\mathrm{V}$ (PRINS, 1992).

VI (BRAUDEL, 1978).

VII (CERTEAU, 2006).

VIII (DECCA; SAVIANI; LOMBARDI, 2006, p. 23).

IX (LOPES; GALVÃO, 2001, p.77).

$\mathrm{X}(2003)$.

XI $(2004$, p.5).

XII (2006).

XIII (BACELLAR, 2006, p. 64).

XIV (LOPES; GALVÃO, 2001, p. 92).

XV (LOPES; GALVÃO, 2001, p. 92).

XVI (CARVALHO et al., 2011, p. 58-59).

XVII (2000, p. 8-9).

XVIII Todas essas referências estão relacionadas à produção científica no Brasil em termos de História da Educação do período compreendido de 1978-1998. Foram retiradas da obra de Lombardi (2000).

XIX (INEP, 2017).

XX (INEP, 2017).

XXI HISTEDBR.

XXII HISTEDBR.

XXIII (2012).

XXIV (BICA; RESCHKE, 2012, p.13).

XXV Diretório dos Grupos de Pesquisa no Brasil constitui-se no inventário dos grupos de pesquisa científica e tecnológica em atividade no País. As informações nele contidas dizem respeito aos recursos humanos constituintes dos grupos (pesquisadores, estudantes e técnicos), às linhas de pesquisa em andamento, às especialidades do conhecimento, aos setores de aplicação envolvidos, à produção científica, tecnológica e artística e às parcerias estabelecidas entre os grupos e as instituições, sobretudo com as empresas do setor produtivo. Com isso, é capaz de descrever os limites e o perfil geral da atividade científico-tecnológica no Brasil. Fonte: http://lattes.cnpq.br/web/dgp/home.

XXVI DGP/CNPq.

XXVII (SBHE, 2017).

XXVIII (LOMBARDI, 2000, p.18).

XXIX (CARVALHO et al., 2011, p.58).

XXX (CARVALHO et al, 2011, p. 59).

$\mathrm{XXXI}$ et al., (2011).

\section{Referências}

BACELLAR, Carlos. Fontes documentais: Uso e mal-uso dos arquivos. In: PINSKY, Carla Bassanezi (Org.). Fontes históricas. São Paulo: Contexto, 2006.

BICA, Carvalho Alessandro; RESCHKE, Maria Janine Dalpiaz. A PESQUISA EM HISTÓRIA DA EDUCAÇÃO: CAMINHOS, ETAPAS E ESCOLHAS NO TRABALHO DO HISTORIADOR. Seminário de Pesquisa em Educação Região Sul: IX ANPED SUL, UNIPAMPA, 2012. Disponível em: $<$ http://www.portalanpedsul.com.br/admin/uploads/2012/GT02_Historia_da_Educaca o/Trabalho/03_40_18_GT02_Alessandro_Bica.pdf $>$. Acesso em 20/02/2017.

Cadernos do Tempo Presente, São Cristóvão-SE, v. 09, n. 01, p. 92-106, jan./jun. 2018| http://www.seer.ufs.br/index.php/tempo 
BRAUDEL, Fernand. Escritos sobre a História. São Paulo: Perspectiva, 1978.

CARVALHO, Carlos Henrique de; GATTI JÚNIOR, Décio; INÀCIO FILHO, Geraldo; ARAÚJO, José Carlos Souza; GONÇALVES NETO, Wenceslau. HISTÓRIA DA EDUCAÇÃO NO BRASIL: PESQUISA, ORGANIZAÇÃO INSTITUCIONAL E ESTRATÉGIAS DE DIVULGAÇÃO CIENTÍFICA. Uberlândia-MG: Cadernos de História da Educação - UFU, v. 10, n.2, p. 45-67, jul./dez, 2011. Disponível em:

$<$ www.seer.ufu.br/index.php/che/article/download/14632/8372>. Acesso em: $10 / 02 / 2017$.

CERTEAU, Michel de. A escrita da História. 2.ed. - Rio de Janeiro: Forense Universitária, 2006.

DECCA, Edgar S.; SAVIANI, Dermeval; LOMBARDI, José C. História e História da Educação. Campinas-SP: Autores Associados, 2006.

DGP/CNPq. Disponível em:< http://lattes.cnpq.br/web/dgp>. Acesso em: 28/02/2017.

HISTEDBR. Disponível em:< http://www.histedbr.fe.unicamp.br/ > Acesso em: $28 / 02 / 2017$

INEP. Disponível em: $<$ http://inep.gov.br/web/guest/educacao-superior $>$. Acesso em: 28/02/2017.

KUNH, Thomas S. A estrutura das revoluções científicas. São Paulo: Perspectivas, 2010.

LANGLOIS, Ch. V. SEIGNOBOS, Ch. Introdução aos Estudos Históricos. São Paulo: Renascença, 1946.

LE GOOF, Jacques. História e Memória. Campinas-SP: Editora da Unicamp, 2003.

LOPES, Eliane Marta Teixeira; GALVÃO, Ana Maria de Oliveira. História da Educação. Rio de Janeiro: DP\&A, 2001.

LOMBARDI, José Claudinei. Pesquisa em educação: história, filosofia e temas transversais. Campinas-SP: Autores associados, 2000.

PRINS, Gwyn. HISTÓRIA ORAL. In: BURKE, Peter (Org.). A Escrita da história: novas perspectivas. São Paulo: Editora da UNESP, 1992.

SAVIANI, Dermeval. Breves considerações sobre fontes para a História da Educação. In. LOMBARDI, José Claudinei; NASCIMENTO, Maria Isabel Moura. Fontes, história e historiografia da educação. Campinas (SP): Autores Associados, 2004.

SBHE. Disponível em:< http://www.sbhe.org.br/>. Acesso em: 15/02/2017.

Cadernos do Tempo Presente, São Cristóvão-SE, v. 09, n. 01, p. 92-106, jan./jun. 2018| http://www.seer.ufs.br/index.php/tempo 